\title{
Lysosomal Function and Dysfunction: Mechanism and Disease
}

\author{
Patricia Boya
}

\begin{abstract}
Significance: Lysosomes are organelles in which cellular degradation occurs in a controlled manner, separated from other cellular components. As several pathways terminate in the lysosome, lysosomal dysfunction has a profound impact on cell homeostasis, resulting in manifold pathological situations, including infectious diseases, neurodegeneration, and aging. Recent Advances: Lysosomal biology demonstrates that in addition to regulating the final steps of catabolic processes, lysosomes are essential up-stream modulators of autophagy and other essential lysosomal pathways. Future Directions and Critical Issues: Lysosomal membrane permeabilization offers therapeutic potential in the treatment of cancer, though the molecular regulators of this process remain obscure. This review focuses on recent discoveries in lysosomal function and dysfunction, primarily in in vivo situations. Antioxid. Redox Signal. 17, 766-774.
\end{abstract}

\section{Introduction: The Lysosome}

L YSOSOMES ARE CYTOPLASMIC membrane-enclosed organelles containing hydrolytic enzymes that degrade macromolecules and cell components (38). These organelles were discovered by Christian de Duve over 60 years ago, for which, among other discoveries, he received the Nobel Price award in 1974 (5). For some time the lysosome was considered the final destination of degradative pathways. However, interest in this organelle has been revived due to its implication in a plethora of important processes in cells and tissues. This review will summarize some of the recent findings demonstrating the importance of lysosomes in many physiological conditions and the role of lysosomal dysfunction in pathological conditions.

With the exception of erythrocytes, lysosomes are found in all eukaryotic cell types. However, not all lysosomes are alike and some have acquired specific functions in given cell types, such as melanosomes and lytic granules, which are modified lysosomes also known as lysosome-related organelles (38). Lysosomes contain many different hydrolytic enzymes, including proteases, lipases, nucleases, glycosidases, phospholipases, phosphatases, and sulfatases, which usually exert maximal enzymatic activity at low $\mathrm{pH}$. This acidic milieu of lysosomes $(\mathrm{pH} \leq 5)$ is maintained by a vacuolar ATPase that pumps protons from the cytoplasm into the lysosomal lumen (38). Other important lysosomal components include lysosomal membrane proteins that play diverse and crucial roles in lysosome homeostasis. These proteins, such as Lamp-1 and Lamp-2, are heavily glysosylated and hence resist digestion, protecting the lysosomal membrane from acidic hydrolases (38) and agents that can damage the lysosome (8). Lysosomal membrane proteins also regulate lysosomal movement, cellular distribution, and exocytosis (38).

How lysosomal biogenesis occurs is not completely understood (38). A recent report shows that site-1 protease (S1P), a metalloprotease embedded in the Golgi membrane that regulates cholesterol metabolism, is required for lysosome biogenesis. Cells lacking S1P display a characteristic lysosomal defect; rather than being targeted to the organelle, certain lysosomal enzymes are secreted out of the cells (22). New evidence demonstrates that many lysosomal genes are regulated in a coordinated fashion by transcription factor EB (TFEB) (42). This transcription factor, which belongs to the microphatalmia-transcription factor E family, binds to a palindromic $10 \mathrm{bp}$ sequence (known as the CLEAR element), which is found in many lysosomal genes, including cathepsines and lysosomal membrane proteins (42). Overexpression of TFEB in HeLa cells induces a clear expansion of the lysosomal compartment and increases the number of lysosomes per cell. This transcription factor translocates to the nucleus after lysosomal stress and exhibits a predominantly nuclear distribution in MEFs from patients with several forms of lysosomal storage diseases (LSD) (42). In addition to regulating lysosomal genes, TFEB also regulates the expression of several autophagy-related genes in nutrientdeprived conditions, in which autophagy is activated as a cytoprotective response (43). Interestingly, TFEB also links mTOR to V-ATPase expression and endocytosis (33). Thus, by regulating lysosomal biogenesis, TFEB emerges as an

Department of Cell Proliferation and Development, Centro de Investigaciones Biológicas, CSIC, Madrid, Spain. 
FIG. 1. Pathways converging in lysosomes.

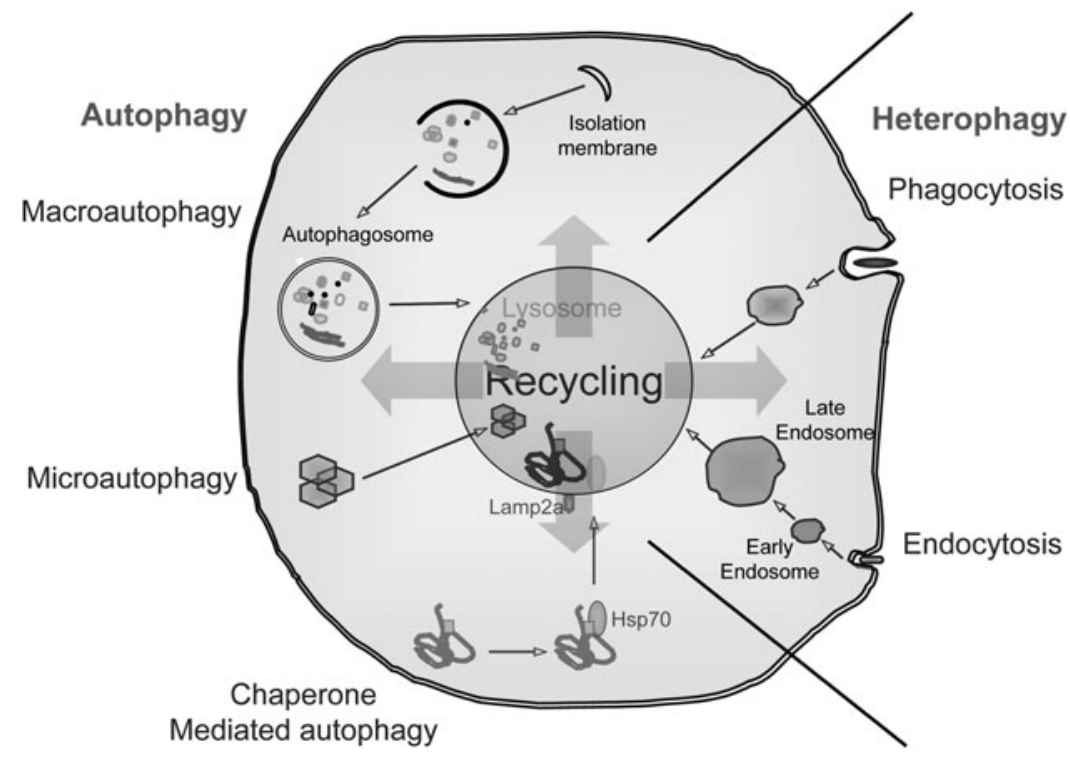

essential coordinator of the autophagy-lysosomal response after stress.

\section{Pathways Converging in Lysosomes}

Several degradation pathways converge at the level of the lysosome, including endocytosis, phagocytosis, and autophagy (Fig. 1). The two first pathways degrade components from the extracellular milieu (heterophagy), while macro-, micro-, and chaperone-mediated autophagy (CMA) mainly degrade intracellular components (49). During macroautophagy cytoplasmic components, damaged proteins and entire organelles are degraded and recycled to generate building blocks for anabolic processes (49). CMA is a process by which cystosolic proteins harboring a motif with specific amino acid sequences are incorporated into lysosomes through the combined action a chaperone (usually Hcs70) and the lysosomal receptor Lamp-2A. Much less is known about microautophagy, whereby macromolecules are directly translocated into the lysosomal lumen for degradation (49).

As the main catabolic organelle in the cell, lysosomes degrade a plethora of compounds, including surface receptors, macromolecules, organelles, and pathogens (Fig. 2), as well as some short-lived proteins previously thought to be degraded by the proteasome system, such as p27 and the small GTPase RhoB $(9,34)$. Lipid modifications in the eight amino acid sequence of the C-terminus of this short-lived GTPase mediate the rapid degradation of both RhoB and chimeric proteins bearing this sequence, via the lysosomal pathway (34). In addition, lysosomes also degrade intracellular organelles that reach the lysosomal lumen trough macroautophagy, such as mitochondria-in a process now called mitophagyribosomes, peroxisomes, and endoplasmic reticulum. Alteration on some of these pathways may have important implication in diseases such as cancer and neurodegeneration.

\section{Lysosomal Function: New Insights}

Several recent findings have demonstrated the central role of the lysosome in controlling cellular responses to nutrients. Mammalian target of rapamycin complex 1 (mTORC1) is a kinase that regulates the cellular response to amino acids, growth factors, and energy levels within the cell. mTORC1 translocates to the lysosomal membrane in the presence of amino acids, where it is activated by its modulator Rheb (41). This translocation is regulated by a multiprotein complex named Ragulator, which serves as an aminoacid-regulated docking site for mTORC1 on lysosomal membranes. At this location mTORC1 phosphorylates downstream effectors that modulate cell metabolism and block autophagy. A recent study by Narita et al. further linked lysosomes and mTORC1 (29), demonstrating that lysosomes spatially link mTOR and autophagy in a compartment known as TOR-autophagy spatial coupling compartment during Ras-induced senescence. This proximity of autolysosomes and the Golgi apparatus to mTORC1 links autophagy-dependent protein degradation to mTOR-dependent secretory protein synthesis. This paradoxical phenotype is observed in senescent cells that display a high

\begin{tabular}{|c|c|}
\hline $\begin{array}{l}\text { Organelle quality control } \\
\text { Macromolecule degradation } \\
\text { Aggregate elimination } \\
\text { Cholesterol homeostasis } \\
\text { Pro-protein processing } \\
\text { Cell survival } \\
\text { mTOR activation } \\
\text { Autophagic cell death }\end{array}$ & Autophagy \\
\hline $\begin{array}{l}\text { Recycling of cell surface receptors } \\
\text { Antigen presentation } \\
\text { Degradation of extracellular matrix } \\
\text { Removal of pathogens }\end{array}$ & Endocytosis/Phagocytosis \\
\hline $\begin{array}{l}\text { Plasma membrane repair } \\
\text { Bone erosion } \\
\text { Tissue remodeling } \\
\text { Metastasis } \\
\text { Fertilization (acrosomes) }\end{array}$ & Exocytosis \\
\hline $\begin{array}{l}\text { Lysosomal membrane } \\
\text { permeabilization }\end{array}$ & Cell death \\
\hline
\end{tabular}

FIG. 2. Lysosomal functions. 
level of autophagy induction and extensive secretory protein synthesis (29).

Other findings have demonstrated the importance of compartmentalization and lysosomal positioning within the cell in controlling cellular nutrient responses (17). In conditions of nutrient starvation, lysosomes cluster in the perinuclear area of the cell, where autophagosomes are predominantly localized. Autophagosome-lysosome fusion permits degradation and recycling to provide new building blocks and maintain cell functions. In nutrient-rich conditions, however, lysosomes move along microtubules to a more peripheral localization (17). Lysosomal positioning regulates mTOR signaling; recovery after starvation restores lysosomal localization of mTORC1 and its autophagy-inhibiting activity (17). The reverse, however, does not hold true; mTORC1 activity does not influence lysosomal localization or redistribution, pointing to the lysosome as the upstream regulator of this process (17). Yu et al. further linked mTORC1 to the lysosome, demonstrating that despite an initial period of mTORC1 inhibition shortly after nutrient starvation $(2 \mathrm{~h})$, longer incubation in these conditions (over $6 \mathrm{~h}$ ) induces mTORC1 activation, as evidenced by an increase in the phosphorylation of its downstream target S6K (50). More importantly, this effect is dependent on the autophagy regulators Atg5 and Atg7 and on lysosomal proteolysis, indicating that autophagy and lysosomal degradation regulate mTORC1 activation to terminate the autophagic process (50). Lysosomes thus control both the final step during nutrient starvation (lysosomal degradation) and the initiation of the process (autophagy induction).

$\mathrm{Yu}$ and colleagues also provided new clues regarding the recycling of lysosomal proteins and the membrane during starvation. They define the concept of autophagic lysosome reformation (ALR) as an evolutionarily conserved regeneration mechanism that controls nutrient sensing and lysosome homeostasis after nutrient deprivation $(37,50)$. During mTORC1 activation after prolonged starvation, tubular structures protrude from the autolysosomal membranes, growing to form vesicles that finally pinch off to give rise to protolysosomes. These new isolated organelles are positive for lysosomal membrane markers such as Lamp-1, though they do not stain for the acidic probe LysoTracker Red or endocytosed dextrans, indicating that these structures permit recycling of lysosomal membrane but not the autolysosomal contents (50). Incubation with rapamycin during starvation prevents ALR, indicating that this process is mTORC1 dependent. mTORC1-regulated ALR thus provides feedback inhibition to terminate autophagy after prolonged starvation, as well as mediating recycling of the lysosomal membrane and membrane proteins through the formation of protolysosomes from the autophagolysosomal membrane (50). Recently, the lysosomal permease Spinster was identified as the regulator of $\mathrm{mTORC} 1$ reactivation and ALR following prolonged starvation (37). Taken together, this new evidence points to lysosomes, not upstream regulators, as essential and active players in the control of cellular responses to nutritional stress.

\section{Lysosomal Pathways in Development and Differentiation}

Few studies have addressed the role of lysosomal function during development. Cathepsin D (CD) and the acid-DNAse
II appear to be overexpressed in areas of prominent cell death during limb and heart development (27). CD is expressed during insect metamorphosis in a tissue-specific and developmental-stage-specific manner, and transcriptionally regulated by the hormone ecdysone. RNAi depletion of CD arrests larval-pupal metamorphosis and abolishes DNA fragmentation (12). Cathepsin activity during insect development may be related to the involvement of autophagy and lysosome degradation in Drosophila metamorphosis, in which both autophagy and caspases play prominent roles (24). The roles of lysosomes and autophagy during development appear to be related to programmed cell death. Indeed, autophagy is indispensable for apoptotic cell removal during retinal development (25), though this effect appears to be specific to cell death in neuroblasts and recently born neurons, without affecting the elimination of apoptotic bodies from mature neurons (26). A similar phenotype of defective clearance has been described in a Drosophila model of the LSD Mucolipidosis type IV (44).

During development cell fate decisions influenced by morphogens are required for embryo patterning. Recent evidence demonstrates that the rate at which internalized morphogen receptors are trafficked to lysosomes is crucial for sensing morphogen gradients during development (32). Other studies have demonstrated the importance of the endolysosomal pathway for axon pathfinding and synapse formation. Loss of the neuron-specific v-ATPase subunit a1 in Drosophila leads to the progressive accumulation of the endosomal guidance receptor, altering its turnover and signaling after neuronal differentiation (47). Recent findings have also demonstrated a key role for lysosomes in mammary gland remodeling after lactation (see below). Lysosomes thus play different roles during development and differentiation, detecting morphogen gradients, remodeling intracellular components during cell differentiation, and participating in cell demise, either by directly inducing cathepsin-dependent cell death or by degrading apoptotic cells.

\section{The Roles of Lysosomes in Programmed Cell Death: Lysosomal Membrane Permeabilization}

Given their high levels of hydrolytic enzymes, lysosomes are potentially harmful to the cell (3). Damage to the lysosomal membrane results in the release of its contents into the cytoplasm, inducing indiscriminate degradation of cellular components. Moreover, massive lysosomal breakdown may induce cytosolic acidification, which in turn can induce cell death by necrosis (Fig. 3). This concept was first described by Christian de Duve, who termed lysosomes "suicide bags" (5). However, as discussed in the proceeding section, partial and selective lysosomal membrane permeabilization (LMP) induces controlled cell death.

LMP provokes the translocation of lysosomal contents to the cytoplasm. The proteases implicated in cell death are cathepsins that remain active at neutral $\mathrm{pH}$, such as cathepsin $\mathrm{B}$, $\mathrm{CD}$, and cathepsin L (3). These proteases trigger a cascade of events culminating in the activation of apoptotic effectors (Fig. 3), including mitochondria, caspases, and other asyet-unknown effectors (3). Specific methods to identify LMP in cells and tissues have been previously reviewed $(3,13)$.

A continually growing list of compounds can induce LMP $(3,10,14)$. An updated list of those classified according to 
FIG. 3. Cell death pathways after lysosomal membrane permeabilization.

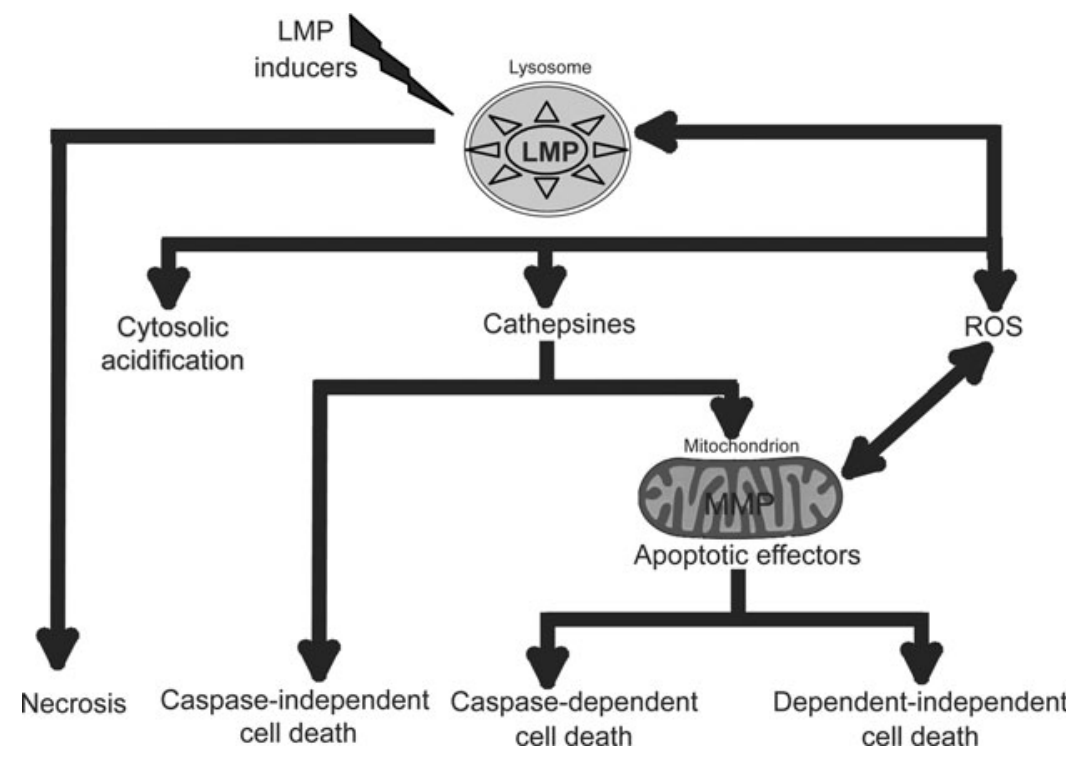

family is shown in Figure 4. However, the role of these compounds in inducing LMP will not be discussed here. Cells also contain endogenous inhibitors that can protect against lysosomal damage; the Hsp70 family of chaperones has been shown to protect lysosomal membranes from damaging agents (16). Moreover, by binding to the lysosomal lipid anionic phospholipid bis(monoacylglycero)phosphate, recombinant Hsp70 can reverse the phenotype seen in patients with Niemann-Pick disease A, an LSD associated with decreased lysosomal stability (16). Calpain-mediated cleavage of Hsp70 was recently described in CA1 neurons of the monkey hippocampus after ischemia-reperfusion insult (39). Further supporting the protective role of Hsp70 in lysosomal function, 2-phenylethynesulfonamide, an inhibitor of the Hsp70 activity, suppresses tumor development in vivo (20).

Although numerous studies have demonstrated lysosomalmediated cell death in culture, no clear evidence of LMP has been reported during physiological cell death. Recently, LMP-induced cell death has been implicated in the regression of the mammary gland after lactation (18). This process occurs upon weaning and involves the controlled elimination of mammary gland cells by programmed cell death. In the first phase of postlactation regression, lysosomes become leaky and cathepsines B and L are translocated to the cytoplasm, inducing caspase-independent cell death. The molecular regulation of this LMP remains elusive, though a

FIG. 4. Agents that induce lysosomal membrane permeabilization.

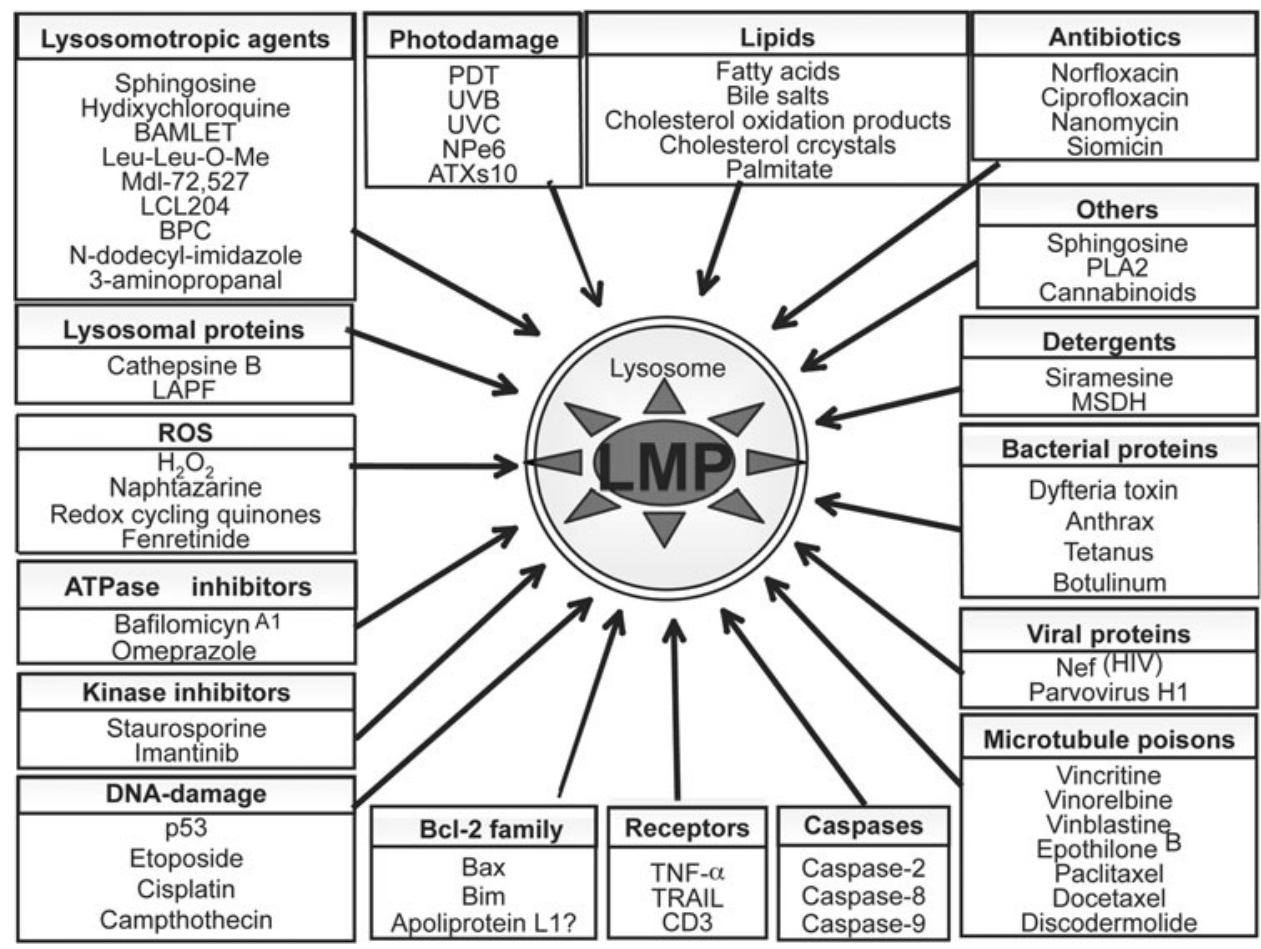


Table 1. Recently Described Models and Diseases Associated with Lysosomal Dysfunction

\begin{tabular}{|c|c|c|c|c|c|}
\hline Disease & Model & Cause & $\begin{array}{l}\text { Lysosomal } \\
\text { dysfunction }\end{array}$ & Consequences & Reference \\
\hline $\mathrm{AD}$ & PS1 mutation & $\begin{array}{l}\text { Presenilin } 1 \\
\text { mutations }\end{array}$ & $\begin{array}{l}\text { Increased } \mathrm{pH} \text { by de- } \\
\text { creased lysosomal } \\
\text { ATPase expression }\end{array}$ & $\begin{array}{l}\text { Autophagy block, } \\
\text { neurodegeneration }\end{array}$ & (30) \\
\hline $\mathrm{AD}$ & $\begin{array}{l}\text { Fly, mouse and } \\
\text { sheep models of } \\
\text { CD deficiency }\end{array}$ & $\begin{array}{l}\text { Tau cleavage, } \\
\text { caspase activation }\end{array}$ & Defect in CD & Neurodegeneration & (15) \\
\hline $\begin{array}{l}\text { Synuclenopathies/ } \\
\text { Gaucher disease }\end{array}$ & $\begin{array}{l}\text { Glucocerebrosidase } \\
\text { deficiency/Gau- } \\
\text { cher disease mice } \\
\text { and patients }\end{array}$ & $\begin{array}{l}\text { Glucocerebrosidase } \\
\text { deficiency }\end{array}$ & $\begin{array}{l}\text { Inhibition of lyso- } \\
\text { somal activity }\end{array}$ & $\begin{array}{l}\alpha \text {-synuclein accumu- } \\
\text { lation, neurode- } \\
\text { generation }\end{array}$ & (23) \\
\hline PD & $\begin{array}{l}\mathrm{MMP}+\text { treated } \\
\text { mice/PD patients }\end{array}$ & $\begin{array}{l}\text { Oxidative stress? } \\
\text { Mitochondrial } \\
\text { damage? }\end{array}$ & LMP & $\begin{array}{l}\text { Autophagy block, } \\
\text { neurodegeneration }\end{array}$ & (7) \\
\hline Lafora disease & EPM2A (laforin-/-) & $\begin{array}{l}\text { Decreased laforin } \\
\text { expression }\end{array}$ & $\begin{array}{l}\text { Decreased autop- } \\
\text { hagy, ubiquitin } \\
\text { accumulation }\end{array}$ & $\begin{array}{l}\text { Glycogen storage } \\
\text { disease, neurode- } \\
\text { generation }\end{array}$ & (1) \\
\hline $\begin{array}{l}\text { Mucolipidosis } \\
\text { type IV }\end{array}$ & Drosophila & $\begin{array}{l}\text { Secondary death in } \\
\text { adjoining cells }\end{array}$ & $\begin{array}{l}\text { Defective clearance } \\
\text { of apoptotic cells }\end{array}$ & Motor deficits & $(44)$ \\
\hline Mucolipidosis II? & S1P deficient cells & $\begin{array}{l}\text { Defects in the target- } \\
\text { ing of lysosomal } \\
\text { enzymes }\end{array}$ & $\begin{array}{l}\text { Lysosomal dysfunc- } \\
\text { tion }\end{array}$ & $\begin{array}{c}\text { Lysosomal enzyme } \\
\text { targeting defects }\end{array}$ & $(22)$ \\
\hline $\begin{array}{l}\text { Pneumococcal } \\
\text { infection }\end{array}$ & $\mathrm{CD}-/-$ & Cathepsin deficiency & $\begin{array}{l}\text { Infected macrophage } \\
\text { LMP }\end{array}$ & $\begin{array}{l}\text { Decreased } \\
\text { apoptosis of } \\
\text { macrophages and } \\
\text { bacterial killing }\end{array}$ & $(2)$ \\
\hline $\begin{array}{l}\text { Ischemia-reperfusion } \\
\text { insult }\end{array}$ & $\begin{array}{l}\text { Monkey hippocam- } \\
\text { pal CA1 neurons }\end{array}$ & $\begin{array}{l}\text { Cleavage of Hsp70 } \\
\text { by calpain }\end{array}$ & LMP & Neurodegeneration & (39) \\
\hline
\end{tabular}

$\mathrm{AD}$, Alzheimer's disease; CD, cathepsin D; LMP, lysosomal membrane permeabilization; MMP+, N-methyl-4-phenylpyridinium; S1P, site-1 protease; PD, Parkinson's disease.

decrease in the expression of the lysosomal membrane protein Lamp-2, which precedes LMP in other systems (7), is observed after lactation. In addition to the increased sensitivity to LMP during involution of the mammary gland, the expression profile of protein precursors of cathepsines B and $\mathrm{L}$ increases sharply after weaning, accompanied by an increase in the presence of the active forms in the supernatant of purified lysosomes, indicating lysosomal leakage (18). Kreuzaler and colleagues further demonstrated that Stat3 controls the expression of these proteins and that specific deletion of this transcription factor in the mammary gland significantly delays postlactation regression. More importantly, in vivo administration of the cathepsine B inhibitor CA-074-Me significantly delays cell death and the regression of the mammary gland, indicating that LMP is a crucial event in this process (18). These recent findings link Stat3 with LMP in a physiological cell death paradigm. Whether these findings can aid the search for new therapies for mammary tumors remains to be demonstrated. While caspases are activated during mammary gland involution, postlactation regression proceeds as normal in caspase-deficient animals, suggesting that caspase activation during this process may be a consequence, rather than a cause, of cell death (18). Besides classical morphology of apoptotic cells, studies using bovine mammary gland remodeling have identified cells loaded with autophagosomes that would be classified as undergoing type-II or autophagic cell death according to the old-morphological definitions of cell death.
Autophagy induction as determined by electron microscopy, as well as LC3 and Beclin1 upregulation, is observed during mammary gland remodeling. However, careful examination indicates that the autophagy process may be activated as a consequence of cell starvation or as a cytoprotective mechanism to prevent cell death (28). Whether autophagy also provides an efficient mechanism for cell remodeling during mammary gland involution remains to be elucidated.

Relatively few in vivo studies have addressed the relationship between lysosomal membrane destabilization and pathogenic cell death [for early reports please refer to Ref. (3)]. A recent report demonstrates that LMP followed by CDdependent macrophage killing is essential for clearance of pneumococcal infection in vivo (2). While LMP clearly induces cell death, the molecular events that lead to lysosomal membrane leakage remain obscure; LMP may occur through nonselective rupture of the membrane or alternatively, though the formation of specific pores that allow the selective translocation of molecules up to a certain size through the partially permeable lysosomal membrane.

\section{Lysosomes in Cancer Therapy}

The capacity of lysosomes to kill cells through LMP has been exploited in the development of cancer treatments. A wide variety of agents can kill cancer cells in vitro [for reviews see Refs. (3, 10)] (Fig. 4). To develop efficient and nontoxic cancer therapies, a distinction must be made between healthy 
and tumor cells, since all cells contain lysosomes. However, lysosomes from cancer cells exhibit several properties that differ from those of un-transformed cells, which may be exploited in therapeutic strategies. During cellular transformation, cancer cells undergo profound lysosomal changes, affecting size, intracellular localization, cathepsin expression, and enzymatic activity. Moreover, several findings suggest that lysosomes from cancer cells may be more susceptible to LMP. For example, the increased size of lysosomes in cancer cells renders them more susceptible to destabilizing agents (11). Furthermore, mutations that disrupt components of the lysosomal degradation pathway were found to contribute to tumor development and progression in a genetic screen performed in Drosophila (4). A recent report demonstrated that autophagy induction and LMP-dependent cell killing mediate the antitumoral effects of the cannabinoid delta(9)tetrahydrocannabinol (THC) against glioma (40). Moreover, a strategy combining Akt inhibition with lysosomotropic agents that disturb lysosomal stability (chloroquine) exerted antitumoral effects in vivo (6). Exploitation of LMP-mediated cell killing for cancer therapy thus represents a new and potentially beneficial therapeutic avenue for the treatment of human tumors.

\section{Lysosomal Dysfunction}

LSDs are pathologies in which a lysosomal defect provokes aberrant intra-lysosomal accumulations of undigested materials. To date, over 50 monogenic human genetic diseases associated with lysosomal dysfunctions have been identified. Although these diseases are triggered by a monogenic mutation, the underlying molecular and cellular events are highly complex and remain unclear (46). The most common mutations in these diseases are found in soluble lysosomal enzymes, nonenzymatic lysosomal proteins (soluble or membrane-bound), and nonlysosomal proteins that regulate lysosomal functions such as lysosomal protein trafficking (46). These diseases are inherited in an autosomal recessive manner, and the residual activity of the mutated protein determines the disease penetrance. Null mutations trigger symptoms in utero or during early childhood, while milder mutations lead to juvenile or adult onset disease (46). The downstream consequences of LSD usually include altered lipid trafficking, calcium homeostasis, and inflammation that contribute to pathogenesis (46). Moreover, since lysosomes are the final step in the autophagy process, lysosomal alterations have profound defects on autophagy and autophagosome accumulation, as has been reported in many LSDs (Table 1).

Neurodegeneration associated with lysosomal and autophagy dysfunction has been well documented $(31,36)$. Alzheimer's disease (AD) is the most common cause of dementia, the prevalence of which increases with age. Several observations point to defective lysosomal function in this disease (30). Furthermore, an unexpected link has been reported between $\mathrm{AD}$ and defective lysosomal proteolysis associated with reduced acidification of lysosomes (19). The presenilin 1 protein, which is often mutated in $\mathrm{AD}$, is essential for translocation of the v-ATPase V0a1 subunit to lysosomes (19). Reduced levels of this lysosomal ATPase decrease lysosomal acidification, hampering protease activation and blocking lysosomal function (19). Accordingly, presenilin 1 deletion reduces the degradation of autophagic/lysosomal substrates. Similar autolysosome maturation defects have been described in neurons in the brains of mouse models of PS1 hypofunction and in cells from AD patients with presenilin 1 mutations. A further link between AD and lysosomal activity is suggested by recent evidence demonstrating abnormal C-terminal truncation of tau and accompanying caspase activation in CDdeficient animals (15). Moreover, in mice with genetic deletion of cystatin B, an endogenous inhibitor of lysosomal cysteine proteases, abnormal accumulations of amyloid- $\beta$ peptide, ubiquitinated proteins, and other autophagic substrates within autolysosomes/lysosomes are attenuated, and neurodegeneration-associated learning and memory defects prevented (48). Together, these findings support the role of proper lysosomal function in preventing neurodegeneration.

In a mouse model of Parkinson's disease (PD), autophagosome accumulation and dopaminergic cell death is preceded by a marked decrease in levels of the lysosomal proteins Lamp-1 and Lamp-2, and a reduction in lysosomes within dopaminergic neurons (7). Lysosomal depletion occurs secondary to the abnormal permeabilization of lysosomal membranes induced by increased mitochondrial-derived reactive oxygen species. LMP resulted in defective clearance and subsequent accumulation of undegraded autophagosomes and contributed directly to neurodegeneration by subsequent ectopic release of lysosomal proteases into the cytoplasm (7). Lysosomal breakdown and autophagosome accumulation is also observed in PD brain samples, in which Lewy bodies are strongly immunoreactive for autophagosomal markers. Importantly, induction of lysosomal biogenesis by genetic or pharmacological activation of lysosomal TFEB restores lysosomal levels, increases autophagosome clearance, and attenuates cell death. The autophagy-enhancer compound rapamycin attenuates PD-related dopaminergic neurodegeneration, both in vitro and in vivo, by restoring lysosomal levels. Similar changes occur in PD brain samples, in which Lewy bodies appear to derive from undegraded autophagosomes (7). These results indicate that autophagosome accumulation in PD results from defective lysosomalmediated autophagosome clearance secondary to lysosomal depletion. Restoration of lysosomal levels and function may thus represent a novel neuroprotective strategy for the treatment of PD (45).

Pathologic accumulation of alpha-synuclein is a feature of PD and other neurodegenerative diseases called synucleinopathies. In vivo, this protein is degraded by lysosomal pathways and in particular by CMA (21). A link between $\alpha$ synucleinopathies and LSD was recently proposed. $\alpha$-synuclein accumulation is associated with a reduction in the expression of glucocerebrosidase, the lysosomal enzyme mutated in Gaucher disease (23). Biochemical analysis demonstrated that glucocerebrosidase deficiency increases the levels of soluble $\alpha$ synuclein oligomers, resulting in aggregation-dependent neurotoxicity. This was a specific effect, as general lysosomal inhibition with leupeptin increased the levels of insoluble forms only. Moreover, a-synuclein inhibited the lysosomal activity of glucocerebrosidase, generating a positive feedback loop and leading to neurodegeneration. Taken together, these findings demonstrate a key role of glucocerebrosidase depletion in the pathogenesis of sporadic synucleopathies (23).

Lafora disease is a fatal autosomal recessive genetic disorder also known as Lafora progressive myoclonic epilepsy. The 
disease is characterized by the presence of inclusion bodies, known as Lafora bodies, within the neurons and cells of the heart, liver, and skin. Mutations in this pathogenic condition occur in the EPM2A and EPM2B genes, which encode the laforin and malin proteins, respectively. Patients with Lafora disease suffer a neurodegenerative disorder associated with progressive intellectual decline and ataxia in addition to epilepsy. Lafora bodies are composed of abnormal glycogen accumulations called polyglucosans, which are insoluble and thus precipitate inside cells. Although the molecular pathogenesis of the disease remains poorly understood, it has been proposed to be a defective clearance disorder. In addition to enzymatic degradation in the cytosol, glycogen is degraded in lysosomes by acid alpha-glucosidase (also known as acid maltase), via the autophagy-lysosomal system. The importance of this autophagy-lysosomal pathway of glycogen degradation is illustrated in glycogen storage disease type II, or Pompe disease, in which this single lysosomal enzyme is lacking (35). Recent studies have demonstrated that laforin regulates autophagy in an mTOR-dependent manner (1). Moreover, cells from laforin-deficient patients and mouse embryonic fibroblasts from laforin-deficient mice exhibit reduced levels of LC3-II and accumulations of poli-ubiquitinated proteins and the autophagy substrate p62 (1). Together, these findings demonstrate the regulatory role of laforin in autophagy and suggest that its absence and the associated defects in autophagy could predispose Lafora disease patients to neurodegeneration. The effect of malin mutations on autophagy and lysosomal pathways in Lafora disease remains to be elucidated. Lysosomal dysfunction thus appears as a common hallmark in many pathological conditions, including LSD, neurodegeneration, and aging.

\section{Concluding Remarks and Future Directions}

Lysosomes are no longer considered the garbage bags in which cellular waste is disposed, but rather have emerged as crucial regulators of cell homeostasis. Recent findings have demonstrated the coupling of lysosomal biogenesis and the stress response via the transcription factor TFEB, and new and unexpected links between lysosomes and the essential kinase mTORC1 have been described. Lysosomes regulate mTOR subcellular localization and activity, thus forming a feedback loop that links upstream signals to tightly regulated catabolic reactions. In turn, mTOR controls the recycling of the lysosomal membrane and proteins through the evolutionarily conserved ALR pathway, generating a proto-lysosome that gives rise to a fully functional mature lysosome. Compartmentalization also emerges as a new regulatory control point in lysosome biology. The subcellular localization of lysosomes controls their activity, and physical proximity appears to be important to simultaneously couple protein synthesis and degradation, two processes previously thought to be incompatible.

New evidence has provided proof that LMP occurs in vivo during physiological cell death in mammary gland involution. Whether this can be exploited for new therapies against mammary and other tumors remains to be demonstrated. Lysosomal dysfunction is a common hallmark associated with many neurodegenerative conditions. Thus, therapies aimed a restoring lysosomal function may have applications for the treatment of diseases such as AD and PD. Further understanding of lysosomal control of other cellular functions and the identification of molecular regulators of LMP and ARL will be essential for the development of new therapies for the treatment of infectious diseases, cancer, neurodegeneration, and aging.

\section{References}

1. Aguado C, Sarkar S, Korolchuk VI, Criado O, Vernia S, Boya P, Sanz P, de Cordoba SR, Knecht E, and Rubinsztein DC. Laforin, the most common protein mutated in Lafora disease, regulates autophagy. Hum Mol Genet 19: 2867-2876, 2010.

2. Bewley MA, Marriott HM, Tulone C, Francis SE, Mitchell TJ, Read RC, Chain B, Kroemer G, Whyte MK, and Dockrell $\mathrm{DH}$. A cardinal role for cathepsin D in co-ordinating the host-mediated apoptosis of macrophages and killing of pneumococci. PLoS Pathog 7: e1001262, 2011.

3. Boya P and Kroemer G. Lysosomal membrane permeabilization in cell death. Oncogene 27: 6434-6451, 2008.

4. Chi C, Zhu H, Han M, Zhuang Y, Wu X, and Xu T. Disruption of lysosome function promotes tumor growth and metastasis in Drosophila. J Biol Chem 285: 21817-21823, 2010.

5. De Duve C and Wattiaux R. Functions of lysosomes. Annu Rev Physiol 28: 435-492, 1966.

6. Degtyarev M, De Maziere A, Orr C, Lin J, Lee BB, Tien JY, Prior WW, van Dijk S, Wu H, Gray DC, Davis DP, Stern HM, Murray LJ, Hoeflich KP, Klumperman J, Friedman LS, and Lin K. Akt inhibition promotes autophagy and sensitizes PTEN-null tumors to lysosomotropic agents. J Cell Biol 183: 101-116, 2008.

7. Dehay B, Bove J, Rodriguez-Muela N, Perier C, Recasens A, Boya P, and Vila M. Pathogenic lysosomal depletion in Parkinson's disease. J Neurosci 30: 12535-12544, 2010.

8. Fehrenbacher N, Bastholm L, Kirkegaard-Sorensen T, Rafn B, Bottzauw T, Nielsen C, Weber E, Shirasawa S, Kallunki T, and Jaattela M. Sensitization to the lysosomal cell death pathway by oncogene-induced down-regulation of lysosome-associated membrane proteins 1 and 2. Cancer Res 68: 6623-6633, 2008.

9. Fuster JJ, Gonzalez JM, Edo MD, Viana R, Boya P, Cervera J, Verges M, Rivera J, and Andres V. Tumor suppressor p27(Kip1) undergoes endolysosomal degradation through its interaction with sorting nexin 6. FASEB J 24: 2998-3009, 2010.

10. Groth-Pedersen L and Jaattela M. Combating apoptosis and multidrug resistant cancers by targeting lysosomes. Cancer Lett 2010 [Epub ahead of print]; DOI: 10.1016/j.canlet.2010 .05.021.

11. Groth-Pedersen L, Ostenfeld MS, Hoyer-Hansen M, Nylandsted J, and Jaattela M. Vincristine induces dramatic lysosomal changes and sensitizes cancer cells to lysosome-destabilizing siramesine. Cancer Res 67: 22172225, 2007.

12. Gui ZZ, Lee KS, Kim BY, Choi YS, Wei YD, Choo YM, Kang PD, Yoon HJ, Kim I, Je YH, Seo SJ, Lee SM, Guo X, Sohn HD, and Jin BR. Functional role of aspartic proteinase cathepsin D in insect metamorphosis. BMC Dev Biol 6: 49, 2006.

13. Ivanova S, Repnik U, Bojic L, Petelin A, Turk V, and Turk B. Lysosomes in apoptosis. Methods Enzymol 442: 183-199, 2008.

14. Johansson AC, Appelqvist H, Nilsson C, Kagedal K, Roberg $\mathrm{K}$, and Ollinger $\mathrm{K}$. Regulation of apoptosis-associated 
lysosomal membrane permeabilization. Apoptosis 15: 527540, 2010.

15. Khurana V, Elson-Schwab I, Fulga TA, Sharp KA, Loewen CA, Mulkearns E, Tyynela J, Scherzer CR, and Feany MB. Lysosomal dysfunction promotes cleavage and neurotoxicity of tau in vivo. PLoS Genet 6: e1001026, 2010.

16. Kirkegaard T, Roth AG, Petersen NH, Mahalka AK, Olsen OD, Moilanen I, Zylicz A, Knudsen J, Sandhoff K, Arenz C, Kinnunen PK, Nylandsted J, and Jaattela M. Hsp70 stabilizes lysosomes and reverts Niemann-Pick disease-associated lysosomal pathology. Nature 463: 549-553, 2010.

17. Korolchuk VI, Saiki S, Lichtenberg M, Siddiqi FH, Roberts EA, Imarisio S, Jahreiss L, Sarkar S, Futter M, Menzies FM, O'Kane CJ, Deretic V, and Rubinsztein DC. Lysosomal positioning coordinates cellular nutrient responses. Nat Cell Biol 13: 453-460, 2011.

18. Kreuzaler PA, Staniszewska AD, Li W, Omidvar N, Kedjouar B, Turkson J, Poli V, Flavell RA, Clarkson RW, and Watson CJ. Stat3 controls lysosomal-mediated cell death in vivo. Nat Cell Biol 13: 303-309, 2011.

19. Lee JH, Yu WH, Kumar A, Lee S, Mohan PS, Peterhoff CM, Wolfe DM, Martinez-Vicente M, Massey AC, Sovak G, Uchiyama Y, Westaway D, Cuervo AM, and Nixon RA. Lysosomal proteolysis and autophagy require presenilin 1 and are disrupted by Alzheimer-related PS1 mutations. Cell 141: 1146-1158, 2010.

20. Leu JI, Pimkina J, Frank A, Murphy ME, and George DL. A small molecule inhibitor of inducible heat shock protein 70 . Mol Cell 36: 15-27, 2009.

21. Mak SK, McCormack AL, Manning-Bog AB, Cuervo AM, and Di Monte DA. Lysosomal degradation of alpha-synuclein in vivo. J Biol Chem 285: 13621-13629, 2010.

22. Marschner K, Kollmann K, Schweizer M, Braulke T, and Pohl S. A key enzyme in the biogenesis of lysosomes is a protease that regulates cholesterol metabolism. Science 333: 87-90, 2011.

23. Mazzulli JR, Xu YH, Sun Y, Knight AL, McLean PJ, Caldwell GA, Sidransky E, Grabowski GA, and Krainc D. Gaucher disease glucocerebrosidase and alpha-synuclein form a bidirectional pathogenic loop in synucleinopathies. Cell 146: 37-52, 2011.

24. McPhee CK, Logan MA, Freeman MR, and Baehrecke EH. Activation of autophagy during cell death requires the engulfment receptor Draper. Nature 465: 1093-1096, 2010.

25. Mellén MA, de la Rosa EJ, and Boya P. The autophagic machinery is necessary for removal of cell corpses from the developing retinal neuroepithelium. Cell Death Differ 15: 1279-1290, 2008.

26. Mellén MA, de la Rosa EJ, and Boya P. Autophagy is not universally required for phosphatidyl-serine exposure and apoptotic cell engulfment during neural development. Autophagy 5: 7, 2009.

27. Montero JA, Lorda-Diez CI, Certal AC, Moreno N, Rodriguez-Leon J, Torriglia A, and Hurle JM. Coordinated and sequential activation of neutral and acidic DNases during interdigital cell death in the embryonic limb. Apoptosis 15: 1197-1210, 2010.

28. Motyl T, Gajewska M, Zarzynska J, Sobolewska A, and Gajkowska B. Regulation of autophagy in bovine mammary epithelial cells. Autophagy 3: 484-486, 2007.

29. Narita M, Young AR, Arakawa S, Samarajiwa SA, Nakashima T, Yoshida S, Hong S, Berry LS, Reichelt S, Ferreira M, Tavare S, Inoki K, Shimizu S, and Narita M. Spatial coupling of mTOR and autophagy augments secretory phenotypes. Science 332: 966-970, 2011.

30. Nixon RA and Yang DS. Autophagy failure in Alzheimer's disease-locating the primary defect. Neurobiol Dis 43: 38-45, 2011.

31. Nixon RA, Yang DS, and Lee JH. Neurodegenerative lysosomal disorders: a continuum from development to late age. Autophagy 4: 590-599, 2008.

32. Nowak M, Machate A, Yu SR, Gupta M, and Brand M. Interpretation of the FGF8 morphogen gradient is regulated by endocytic trafficking. Nat Cell Biol 13: 153-158, 2011.

33. Pena-Llopis S, Vega-Rubin-de-Celis S, Schwartz JC, Wolff NC, Tran TA, Zou L, Xie XJ, Corey DR, and Brugarolas J. Regulation of TFEB and V-ATPases by mTORC1. Embo J 30: 3242-3258, 2011.

34. Perez-Sala D, Boya P, Ramos I, Herrera M, and Stamatakis $\mathrm{K}$. The $\mathrm{C}$-terminal sequence of RhoB directs protein degradation through an endo-lysosomal pathway. PLoS One 4: e8117, 2009.

35. Raben N, Hill V, Shea L, Takikita S, Baum R, Mizushima N, Ralston E, and Plotz P. Suppression of autophagy in skeletal muscle uncovers the accumulation of ubiquitinated proteins and their potential role in muscle damage in Pompe disease. Hum Mol Genet 17: 3897-3908, 2008.

36. Ravikumar B, Sarkar S, Davies JE, Futter M, GarciaArencibia M, Green-Thompson ZW, Jimenez-Sanchez M, Korolchuk VI, Lichtenberg M, Luo S, Massey DC, Menzies FM, Moreau K, Narayanan U, Renna M, Siddiqi FH, Underwood BR, Winslow AR, and Rubinsztein DC. Regulation of mammalian autophagy in physiology and pathophysiology. Physiol Rev 90: 1383-1435, 2010.

37. Rong Y, McPhee CK, Deng S, Huang L, Chen L, Liu M, Tracy K, Baehrecke EH, Yu L, and Lenardo MJ. Spinster is required for autophagic lysosome reformation and mTOR reactivation following starvation. Proc Natl Acad Sci U S A 108: 7826-7831, 2011.

38. Saftig P and Klumperman J. Lysosome biogenesis and lysosomal membrane proteins: trafficking meets function. Nat Rev Mol Cell Biol 10: 623-635, 2009.

39. Sahara S and Yamashima T. Calpain-mediated Hsp70.1 cleavage in hippocampal CA1 neuronal death. Biochem Biophys Res Commun 393: 806-811, 2010.

40. Salazar M, Carracedo A, Salanueva IJ, Hernandez-Tiedra S, Lorente M, Egia A, Vazquez P, Blazquez C, Torres S, Garcia S, Nowak J, Fimia GM, Piacentini M, Cecconi F, Pandolfi PP, Gonzalez-Feria L, Iovanna JL, Guzman M, Boya P, and Velasco G. Cannabinoid action induces autophagy-mediated cell death through stimulation of ER stress in human glioma cells. J Clin Invest 119: 1359-1372, 2009.

41. Sancak Y, Bar-Peled L, Zoncu R, Markhard AL, Nada S, and Sabatini DM. Ragulator-Rag complex targets mTORC1 to the lysosomal surface and is necessary for its activation by amino acids. Cell 141: 290-303, 2010.

42. Sardiello M, Palmieri M, di Ronza A, Medina DL, Valenza M, Gennarino VA, Di Malta C, Donaudy F, Embrione V, Polishchuk RS, Banfi S, Parenti G, Cattaneo E, and Ballabio A. A gene network regulating lysosomal biogenesis and function. Science 325: 473-477, 2009.

43. Settembre C, Di Malta C, Polito VA, Garcia Arencibia M, Vetrini F, Erdin S, Erdin SU, Huynh T, Medina D, Colella P, Sardiello M, Rubinsztein DC, and Ballabio A. TFEB links 
autophagy to lysosomal biogenesis. Science 332: 1429-1433, 2011.

44. Venkatachalam K, Long AA, Elsaesser R, Nikolaeva D, Broadie K, and Montell C. Motor deficit in a Drosophila model of mucolipidosis type IV due to defective clearance of apoptotic cells. Cell 135: 838-851, 2008.

45. Vila M, Bove J, Dehay B, Rodriguez-Muela N, and Boya P. Lysosomal membrane permeabilization in Parkinson disease. Autophagy 7: 98-100, 2011.

46. Vitner EB, Platt FM, and Futerman AH. Common and uncommon pathogenic cascades in lysosomal storage diseases. J Biol Chem 285: 20423-20427, 2010.

47. Williamson WR, Yang T, Terman JR, and Hiesinger PR. Guidance receptor degradation is required for neuronal connectivity in the Drosophila nervous system. PLoS Biol 8: e1000553, 2010.

48. Yang DS, Stavrides P, Mohan PS, Kaushik S, Kumar A, Ohno M, Schmidt SD, Wesson D, Bandyopadhyay U, Jiang Y, Pawlik M, Peterhoff CM, Yang AJ, Wilson DA, St. George-Hyslop P, Westaway D, Mathews PM, Levy E, Cuervo AM, and Nixon RA. Reversal of autophagy dysfunction in the TgCRND8 mouse model of Alzheimer's disease ameliorates amyloid pathologies and memory deficits. Brain 134: 258-277, 2011.

49. Yang Z and Klionsky DJ. Mammalian autophagy: core molecular machinery and signaling regulation. Curr Opin Cell Biol 22: 124-131, 2010.

50. Yu L, McPhee CK, Zheng L, Mardones GA, Rong Y, Peng J, Mi N, Zhao Y, Liu Z, Wan F, Hailey DW, Oorschot V, Klumperman J, Baehrecke EH, and Lenardo MJ. Termination of autophagy and reformation of lysosomes regulated by mTOR. Nature 465: 942-946, 2010.

Address correspondence to: Dr. Patricia Boya Department of Cell Proliferation and Development Centro de Investigaciones Biológicas, CSIC

Ramiro de Maetzu 9

E-28040 Madrid

Spain

E-mail: patricia.boya@csic.es

Date of first submission to ARS Central, November 14, 2011; date of acceptance, November 18, 2011.

$\begin{aligned} & \text { Abbreviations Used } \\ & \mathrm{AD}=\text { Alzheimer's disease } \\ & \mathrm{ALR}=\text { autophagic lysosome reformation } \\ & \mathrm{CD}=\text { cathepsin } \mathrm{D} \\ & \mathrm{CMA}=\text { chaperone-mediated autophagy } \\ & \mathrm{LMP}=\text { lysosomal membrane permeabilization } \\ & \mathrm{LSD}=\text { lysosomal storage disease } \\ & \mathrm{MMP}+=\text { N-methyl-4-phenylpyridinium } \\ & \mathrm{PD}=\text { Parkinson's disease } \\ & \mathrm{S} 1 \mathrm{P}=\text { site-1 protease } \\ & \mathrm{TFEB}=\text { transcription factor } \mathrm{EB}\end{aligned}$

